\title{
Diabetes mellitus juvenil: a experiência de familiares de adolescentes e pré-adolescentes
}

\author{
Juvenile diabetes: \\ the family's experience with diabetic adolescents and pre-adolescents
}

Thaís Basso de Brito ${ }^{1}$

M aria Lúcia Araújo Sadala ${ }^{2}$

${ }^{1}$ Associação das Pioneiras Sociais- RedeSarah de H ospitais de Reabilitação. Av. Luiz Rocha, s/n, M onte Castelo. 65035- 270.

São Luís M A xita_enf@yahoo.com.br ${ }^{2}$ Departamento de Enfermagem, Faculdade de M edicina deBotucatu, UNESP.
Abstract This study aimed at investigating the experience of taking care of adolescents and pre-adolescents with type 1 diabetes from the standpoint of their family members. A phenomenological approach, i.e. a type of qualitative analysis aimed at understanding the meaning of life experiences, was used. Ten parents ( 9 mothers and 1 father) were interviewed at a teaching hospital in the interior of São Paulo state. The experience of taking care of a child with diabetes emerged from the converging points reported under 3 main themes: the universe of the disease; personal relationships; reflections on the experience. The participants described their difficulties and the strategies they use for keeping the family together besides providing support to the children. They believe they have to accept and face the challenges, besides motivating their children in order to ensure their safety and quality of life. The data obtained show the need for professional support as well as for a space for discussing themes of interest, both for the children with diabetes and for their families.

Key words Juvenile diabetes, Experience, Family, Phenomenology
Resumo Esteestudo foi desenvolvido com o objetivo de investigar a experiência de cuidar deadolescentes e pré adolescentes portadores de diabetes tipo I, na perspectiva dos seus familiares. Foi utilizada a abordagem fenomenológica, modalidadede pesquisa qualitativa que se propõe a compreender os significados das experiências vividas. Foram entrevistados dez pais ( 9 mães e 1 pai) em hospital de ensino do interior paulista. A experiência de cuidar do filho com diabetes emerge das convergências das descrições dos participantes, sendo descrita em três temas principais: o universo da doença; relação com as pessoas; reflexão sobre a experiência vivida. Os participantes descrevem suas dificuldades e estratégias para manterem a família unida e ainda oferecer suporte aos filhos. Eles acreditam que têm que aceitar e enfrentar os desafios, além de estimularem os filhos para sua segurança equalidade devida. Os dados mostraram a necessidade de um suporte profissional, além deum espaço para a discussão detemas tanto para as crianças com diabetes como para seus familiares. Palavras-chave Diabetes mellitus tipo I, Experiência, Família, Fenomenologia 
Introdução

0 diabetes mellitus tipo 1 é uma das mais freqüentes doenças crônicas da infância e da adolescência. 0 tratamento para estes pacientes é obrigatório e contínuo. Além da insulina, requer: dieta adequada, atividades físicas regulares, apoio psicológico e social ${ }^{1}$. A pós o diagnóstico, o primeiro contato da criança ou jovem diabético com o profissional de saúde envolve uma atmosfera de ansiedade e dúvidas. A partir desse momento, muito há de se ensinar ao paciente e a seus familiares a respeito da dieta, insulina, testes de urina e de HGT, a fim de diminuir o clima de tensão, ansiedade e dúvidas advindas principalmente dos pais ${ }^{1-2}$. A criança passa a ser o centro das atenções, das angústias e apreensões de seus familiares, o que acaba impregnando 0 ambiente familial. Geralmente, os pais se punem e acabam adotando uma política protecionista em relação à criança, tornando-a dependente 2 .

0 ambiente familiar, tanto no aspecto de relacionamento afetivo-social quanto físico, representa, no todo, uma das mais poderosas forças que influenciam na promoção, proteção e recuperação da saúde ${ }^{2-3}$. Cabe à equipe multidisciplinar orientar os pais quanto às possibilidades de obter ajuda financeira para o tratamento, como insulina, seringas, fitas para mensuração da glicemia. Promover contatos externos com grupos de colônias de férias especializados para crianças e adolescentes diabéticos, assim como com as associações de apoio na comunidade, estimula os pais a utilizarem os recursos disponíveis, de grande valia para a família no cuidado do filho4-5.

Definitivamente, a doença crônica afeta a criança como pessoa e a família como sistema. Compreender e avaliar a vivência familiar no processo de uma doença como o diabetes constitui o alicerce que fundamentará as intervenções dos profissionais da saúde. A família, como coadjuvante primordial na manutenção da qualidade de vida de seus filhos, tem de, abruptamente, aprender a lidar com suas incapacidades, mudanças permanentes e, ainda assim, encontrar um sentido para a doença, que auxilie a si própria, mantendo o controle da situação e não transmitindo ao seu filho insegurança e ansiedade $\mathrm{e}^{6-8}$.

D efinindo como objetivo da assistência capacitar, tanto a criança como seus pais, a desenvolver estratégias que tornem possível a convivência com a doença, os profissionais da saúde têm se preocupado em identificar estratégias que os aproximem das famílias, a fim de compartilhar saberes científicos e culturais. Família unida à equipe de saúde forma uma unidade de cuidado em saúde, auxi- liando a equipe na detecção de problemas e diagnósticos. À família, cabe participar da discussão do diagnóstico, da determinação dos objetivos, colaborando na aplicação do plano de ações e na avaliação dos resultados. Esta interação é de suma importância para o êxito na melhoria das condições de saúde e na qualidade de vida ${ }^{3,7}$.

Considerando 0 exposto anteriormente, este estudo tem como objetivo investigar a percepção dosfamiliares (pai/mãe) a respeito da sua experiência de cuidar dos filhos portadores de diabetes mellitus, considerando que a família, como membro ativo no tratamento da doença, representa um potencial importante no processo de adaptação e busca por melhora da qualidade de vida desses pacientes. Ao procurar conhecer o ponto de vista das famílias, numa abordagem qualitativa, buscamos uma nova perspectiva para conhecer a realidade vivenciada pelos adolescentes e familiares, possi bilitando responder mais efetivamenteàs suas necessidades.

\section{Objetivo}

0 estudo tem como objetivo investigar a experiência de cuidar de adolescentes e pré-adolescentes portadores de diabetes tipo I, na perspectiva dos seus familiares.

\section{M étodo}

0 estudo foi conduzido utilizando o método fenomenológico, abordagem qualitativa que busca compreender os significados das experiências humanas. Na pesquisa fenomenológica, o pesquisador interroga o fenômeno que o inquieta: caminha em direção ao fenômeno, que se manifesta através do sujeito que vivencia a situação ${ }^{9}$. Nesta postura, não se fala, por exemplo, em aprendizagem, em ansiedade, mas sim da experiência de aprender, da experiência de estar ansioso. No nosso estudo, falamos da experiência vivenciada pelo familiar no cuidado ao filho portador de diabetes juvenil. Fala-se, portanto, segundo $\mathrm{M}$ artins e $\mathrm{Bi}$ cudo ${ }^{9}$, do fenômeno situado. Para a análise do fenômeno situado, busca-se uma imersão subjetiva na descrição ou no depoimento dos sujeitos do estudo, procurando apreendêlo inicial mentecomo um todo, e, a seguir, assimilando o conjunto de proposições ontológicas e epistemológicas presentes. A compreensão do fenômeno situado é atingida através de dois momentos: a análise ideográfica - a instância da análise individual de cada depoi- 
mento dos sujeitos da pesquisa; e a análise nomotética - a instância da análise das convergências detodos os depoimentos, momento no qual emergem as verdades gerais que desvelam o fenômeno estudado?.

No presente estudo, foi utilizado o referencial da fenomenologia existencial de M erleau Ponty ${ }^{10}$, fenomenólogo que dá continuidade às idéias fundamentais de H usserl. Baseado na fenomenologia de H usserl, mas indo além dele, a tarefa proposta por M erleau Ponty é o retorno às coisas mesmas, na busca da essência dos objetos e qualidades. Essas coisas são percebidas como parte de um mundo vivido, que constitui o pré reflexivo - a experiência vivida, antes da reflexão - a partir do qual se constroem as ciências. Quando, ao coletarmos os dados para este estudo, solicitamos aos participantes que descrevam a sua experiência de cuidar do filho com diabetes, compreendemos que cada pessoa o faz de acordo com a sua própria percepção do fenômeno, individual eúnica, contextualizada no seu modo de existir no mundo. Essas percepções, dos váriosindivíduos, em diferentes tempos, em diferentes lugares, são perspectivas do fenômeno quese encontram ao serem expressas para o pesquisador, na intersubjetividade, e apresentam convergências e divergências entre si. M ediante as convergências, ou os significados comuns aos indivíduos, podemos chegar aos invariantes do fenômeno, ou às verdades gerais que descrevem a estrutura do fenômeno em estudo. $\mathrm{Na}$ instância seguinte, quando o pesquisador faz a interpretação fenomenológica dos dados, a estrutura do fenômeno é compreendida na perspectiva do pesquisador, queéa perspectiva do conhecimento científico. Esses dados interpretados permitem ao pesquisador chegar ao campo das generalidades, que podemos dizer como pertencenteà estrutura geral do fenômeno.

Nesta perspectiva, refletindo a respeito do tema do nosso estudo, ou seja, como pais vivenciam a experiência de cuidar dos filhos que são diagnosticados com diabetes tipo I, buscamos a compreensão dos significados percebidos pelos mesmos na sua prática desse cuidar, situados no mundo que eles habitam - 0 filho doente, 0 ambiente familiar, a instituição de saúde que oferece assistência ao filho, os profissionais, a sua compreensão da doença e do tratamento - um mundo que já está aí, ao qual énecessário adequar-se para poder atuar sobre ele. Nas suas descrições, procuramos focalizar os seus sentimentos e pensamentos a respeito do que acontece ao seu filho, do seu movimento em ajudá-lo e a reflexão que fazem avaliando e valorando esse cuidado.
Partindo da descrição fenomenológica $3 / 40$ discurso dos participantes da pesquisa a respeito da sua experiência $3 / 4$ e utilizando a redução e a interpretação fenomenológica", alcançamos as unidades designificado que desvelam a compreensão do fenômeno estudado: cuidar do filho portador de diabetes tipo I, na perspectiva dos pais que vivenciam o fenômeno.

\section{Participantes do estudo}

Os dados foram obtidos através de entrevista individual gravada em fita cassete, com mães ou pais que acompanham os filhos no ambulatório de diabetes mellitus tipo i de hospital universitário UNESP - localizado no interior paulista. Este serviço é referência para o tratamento da doença na região oeste do Estado de São Paulo.

Os participantes ( $Q$ uadros 1 e2) foram selecionados segundo os seguintes critérios: ser pai (mãe) de criança/adolescente portador de diabetes tipo I; ter disponibilidade para entrevista com os pesquisadores e tempo de doença do filho maior que um ano. Na definição dos participantes, buscou-se atender à maior amplitude possível quanto à variação das suas características: tempo da doença do filho, controle metabólico, condições socioeconômica e cultural eescolaridadedos pais. Esteúltimo critério visou alcançar resultados, mais abrangentes possíveis, para a compreensão do fenômeno estudado.

O projeto foi aprovado pelo comitê deética em pesquisa da instituição. Os familiares foram esclarecidos quanto ao projeto, seus objetivos, forma, utilização e divul gação dos dados, garantindo-Ihes 0 anonimato e sigilo da sua participação. Tendo concordado, assinaram o termo de consentimento esclarecido.

\section{Procedimentos}

As entrevistas, gravadas em fita cassete, foram realizadas pela primeira autora, em sala do ambulatório do HC, reservada para este fim, com a duração média de cinquenta minutos. A pós a transcrição dos conteúdos, as fitas foram inutilizadas.

A entrevista foi conduzida por uma pergunta norteadora: "Como tem sido a experiência em cuidar do seu filho, portador de diabetes mellitus?". Os depoimentos, reproduzidos exatamente como foram expressos (Quadro 3), foram analisados e interpretados utilizando-se os recursos metodológicosdafenomenologia. Primeiramente, individual- 
mente (análise ideográfica, Quadro 4) utilizandosea redução, análise ea interpretação fenomenológica. A pós a análise de todos os depoimentos, bus- caram-se as convergências das unidades de significado de todos eles (análise nomotética, Quadro 5).

Quadro 1. Descrição dos participantes do estudo.

\begin{tabular}{|l|c|c|l|c|}
\hline Participante & Idade & $\begin{array}{c}\text { Sexo/grau de } \\
\text { parentesco }\end{array}$ & Procedência & Escolaridade/ocupação \\
\hline P 1 & 44 & Feminino (mãe) & Botucatu & Ensino superior/Dona de casa \\
\hline P 2 & 46 & Feminino (mãe) & Bofete & 10 grau/ Empregada doméstica \\
\hline P 3 & 37 & Feminino (mãe) & Jaú & Ensino superior/ D entista \\
\hline P 4 & 34 & Feminino (mãe) & Botucatu & 10 grau incompleto / Faxineira \\
\hline P 5 & 44 & Feminino (mãe) & Jaú & Ensino médio /Funcionária pública \\
\hline P 6 & 47 & Feminino (mãe) & Botucatu & 10 grau incompleto/ Prestadora serviços/ Limpadora \\
\hline P 7 & 40 & Feminino (mãe) & Piraju & 10 grau incompleto / Empregada doméstica \\
\hline P 8 & 63 & Feminino (mãe) & Botucatu & 1o grau incompleto /Dona de casa \\
\hline P 9 & 45 & Masculino (pai) & Botucatu & 1o grau / Pedreiro \\
\hline P 10 & 46 & Feminino (mãe) & Botucatu & Ensino médio /Funcionária pública \\
\hline
\end{tabular}

Quadro 2. Descrição dos filhos dos participantes do estudo.

\begin{tabular}{|c|c|c|c|c|c|c|c|}
\hline Filhos & I dade & Sexo & $\begin{array}{c}\text { Tempo da } \\
\text { doença }\end{array}$ & $\begin{array}{l}\text { Escolaridade/ } \\
\text { ocupação }\end{array}$ & $\begin{array}{l}\text { Principal } \\
\text { cuidador }\end{array}$ & Controle glicêmico & Membros da família \\
\hline P 1 & 24 & M & $5 a$ & $\begin{array}{l}\text { Ensino superior } \\
\text { Adm Empresas }\end{array}$ & M ãe & $\begin{array}{c}\text { HB glicada: } 7,1 \% \\
\text { Glicemia: } 140 \mathrm{mg} / \mathrm{dl}\end{array}$ & $\begin{array}{l}\text { Pai, mãe, irmã (21a), } \\
\text { irmão (12a) }\end{array}$ \\
\hline P 2 & 15 & $M$ & $6 a$ & Estudante & M ãe & $\begin{array}{c}\text { HB glicada: } 5,2 \% \\
\text { Glicemia: } 344 \mathrm{mg} / \mathrm{dl}\end{array}$ & M ãe, pai \\
\hline P 3 & 12 & M & $3 a 6 m$ & Estudante & M ãe & $\begin{array}{c}\text { HB glicada: } 7,1 \% \\
\text { Glicemia: } 125 \mathrm{mg} / \mathrm{dl}\end{array}$ & $\begin{array}{l}\text { Mãe, pai e } 1 \text { irmão } \\
\text { (8a) }\end{array}$ \\
\hline P 4 & 13 & M & $2 a 7 m$ & Estudante & M ãe & $\begin{array}{l}\text { H B glicada: } 6,3 \% \\
\text { Glicemia: } 41 \mathrm{mg} / \mathrm{dl}\end{array}$ & $\begin{array}{l}\text { Pai, mãe e } 1 \text { irmã } \\
(16 a)\end{array}$ \\
\hline P 5 & 18 & $\mathrm{~F}$ & $13 a$ & Ensino médio & M ãe & $\begin{array}{l}\text { HB glicada: 12,8\% } \\
\text { Glicemia: } 155 \text { mg/dl }\end{array}$ & $\begin{array}{l}\text { Pai, mãe, } 1 \text { irmão } \\
\text { (23a), } 1 \text { irmã (17) }\end{array}$ \\
\hline P 6 & 19 & $\mathrm{~F}$ & $10 a$ & $\begin{array}{c}\text { Estudante curso } \\
\text { técnico }\end{array}$ & M ãe & $\begin{array}{l}\text { HB glicada: 9,8\% } \\
\text { Glicemia: } 61 \text { mg/dl }\end{array}$ & Pai, Mãe \\
\hline P 7 & 16 & $\mathrm{~F}$ & $4 a$ & Estudante / babá & M ãe & $\begin{array}{c}\text { HB glicada: } 8,5 \% \\
\text { Glicemia: } 289 \mathrm{mg} / \mathrm{dl}\end{array}$ & Pai, mãe, 1 irmão \\
\hline P 8 & 19 & M & $8 a$ & $\begin{array}{c}\text { Estudante curso } \\
\text { técnico }\end{array}$ & M ãe & $\begin{array}{c}\text { HB glicada: } 6,8 \% \\
\text { Glicemia: } 157 \text { mg/dl }\end{array}$ & Pai, mãe \\
\hline P 9 & 14 & $M$ & 3a & Estudante & M ãe & $\begin{array}{l}\text { HB glicada: } 6,3 \% \\
\text { Glicemia: } 41 \mathrm{mg} / \mathrm{dl}\end{array}$ & $\begin{array}{c}\text { Pai, mãe, } 1 \text { irmã } \\
(16 a)\end{array}$ \\
\hline P 10 & 16 & M & 3a $7 \mathrm{~m}$ & Estudante & M ãe & $\begin{array}{c}\text { HB glicada: } 9,7 \% \\
\text { Glicemia: } 400 \mathrm{mg} / \mathrm{dl}\end{array}$ & $\begin{array}{l}\text { Pai, mãe, } 1 \text { irmão } \\
\text { (12a), } 1 \text { irmão (19a) }\end{array}$ \\
\hline
\end{tabular}

Valores normais glicemia/jejum: 70 - $110 \mathrm{mg} / \mathrm{dl}$; Valor normal H b glicada $<7 \%$ (Fundo Nacional de Saúde) ${ }^{1}$. 
Quadro 3. Depoimento 1.

Nome: R. M. da S. S.; sexo feminino, 44 anos, casada, 3 filhos, 2o grau completo.

Filho: L. A. S., sexo masculino, 24 anos, 3o grau, 5 anos de diagnóstico,controle dos níveis glicêmicos.

“O L. ficou diabético em 2000, há 5 anos trás e desencadeou lá em Porto Seguro. Ele veio pra cá e ficou internado 9 dias até acertar a dose da insulina. É, fácil pra gente não ta sendo, mas a gente supera na medida do possível e... a gente vai levando. Eu só tenho que agradecer a Deus por ser um diabetes e não ser um outro tipo de doença que a gente sabe que não é fácil. E ele leva bem, ele nunca falou: "por que eu, por que eu?". E isso é muito bom, o L. é uma pessoa muito boa. E quanto à família, é lógico, a gente fica tudo limitado porque temos medo dele trabal har e acontecer alguma coisa e é isso... Desses 5 anos ele teve hipoglicemia uma vez e eu não sabia o jeito que era uma hipoglicemia violenta daquele jeito que até acho que foi uma negligência dos médicos por não terem explicado pra gente que uma hipo forte assim... Ele convulsionou, eu coloquei açúcar debaixo da língua dele, logo ele voltou, e quando ele voltou ele não sabia o que tinha acontecido, nada... M as ele leva uma vida normal, dentro do possível. Limitações têm, mas ele ta encarando assim, natural, porque ele sabe que não tem o que fazer. Ele toma a insulina dele, trabalha, terminou a faculdade, então é isso, ele ta bem, graças a Deus. A vida muda um pouco, com relação à alimentação, embora ele não seja de comer muita fruta, verdura, então sempre é uma luta. M as final de semana, não. É aquela preocupação, e a mãe fica preocupada, toda vez que sai, viaja, a gente pede pra avisar onde ta, horário que saiu, horário que chegou... Pra ficar mais tranqüila... 0 meu maior medo é de ter uma hipoglicemia, que ele já teve, e não ter ninguém por perto. Porque aquela hipoglicemia que ele teve, credo! Deixou-me traumatizada e espero que nunca mais ele tenha. 0 tratamento, a gente vê que logo haverá uma possibilidade de cura. M as acho que tem muito comércio dos laboratórios nisso, e não saiu nada ainda. Mas a esperança é que um dia saia porque eles são jovens ainda e têm uma vida inteira pela frente e a gente ta torcendo por isso".

Quadro 4. Análise ideográfica. Depoimento 1.

\begin{tabular}{|c|c|c|c|}
\hline Linguagem do participante & Primeiras elucidações & $\begin{array}{l}\text { Linguagem do } \\
\text { pesquisador }\end{array}$ & $\begin{array}{l}\text { Unidades de significado } \\
\text { (enfoque no fenômeno } \\
\text { estudado) }\end{array}$ \\
\hline $\begin{array}{l}\text { 1. O L. ficou diabético em } 2000 . . . \\
\text { Ficou internado } 9 \text { dias até acertar a } \\
\text { dose da insulina. }\end{array}$ & $\begin{array}{l}\text { M onitorização da glicemia é } \\
\text { necessária para definir dosagem de } \\
\text { insulina. }\end{array}$ & $\begin{array}{l}\text { 1. A doença surgiu há } 5 \\
\text { anos. Foi necessário } \\
\text { interná-lo para definir a } \\
\text { reposição insulínica. }\end{array}$ & $\begin{array}{l}\text { 1.1. O aparecimento do } \\
\text { diabetes é repentino e } \\
\text { inesperado e provoca } \\
\text { hospitalização. }\end{array}$ \\
\hline $\begin{array}{l}\text { 2. Fácil pra gente não tá sendo, } \\
\text { mas a gente supera na medida do } \\
\text { possível e a gente vai levando. }\end{array}$ & $\begin{array}{l}\text { No contexto: para a mãe, há } \\
\text { outras doenças mais graves. }\end{array}$ & $\begin{array}{l}\text { 2. Há dificuldades, que } \\
\text { são enfrentadas dentro } \\
\text { das possibilidades da } \\
\text { família. }\end{array}$ & $\begin{array}{l}\text { 1.2. A família procura } \\
\text { adaptar-se à situação. }\end{array}$ \\
\hline $\begin{array}{l}\text { 3. Eu só tenho que agradecer a } \\
\text { Deus por ser um diabetes e não ser } \\
\text { um outro tipo de doença... }\end{array}$ & & $\begin{array}{l}\text { 3. A mãe agradece a } \\
\text { Deus por não se tratar } \\
\text { de uma doença mais } \\
\text { grave. }\end{array}$ & $\begin{array}{l}\text { 1.3. Há doenças mais } \\
\text { graves que os diabetes. }\end{array}$ \\
\hline $\begin{array}{l}\text { 4. Ele leva bem, ele nunca falou: } \\
\text { "por que eu?". E isso é muito bom, } \\
\text { o L. é uma pessoa muito boa. }\end{array}$ & & $\begin{array}{l}\text { 4. O filho nunca se } \\
\text { mostrou rebelde ou } \\
\text { revoltado diante de sua } \\
\text { situação. }\end{array}$ & $\begin{array}{l}\text { 1.4. } 0 \text { adolescente pode } \\
\text { reagir positivamente } \\
\text { diante da doença. }\end{array}$ \\
\hline $\begin{array}{l}\text { 5. Quanto à família, fica tudo } \\
\text { limitado porque temos medo dele } \\
\text { trabalhar e acontecer alguma coisa } \\
\text { e é isso... }\end{array}$ & $\begin{array}{l}\text { Limitar: Determinar os limites de, } \\
\text { ou servir de limite a. Restringir, } \\
\text { diminuir. Ter como limite } \\
\text { (FERREIRA, 1989). }\end{array}$ & $\begin{array}{l}\text { 5. A mãe sente-se } \\
\text { limitada pela doença e } \\
\text { tem medo de } \\
\text { complicações. }\end{array}$ & $\begin{array}{l}\text { 1.5. A vida da família } \\
\text { passa a centralizar-se na } \\
\text { doença do filho. }\end{array}$ \\
\hline
\end{tabular}




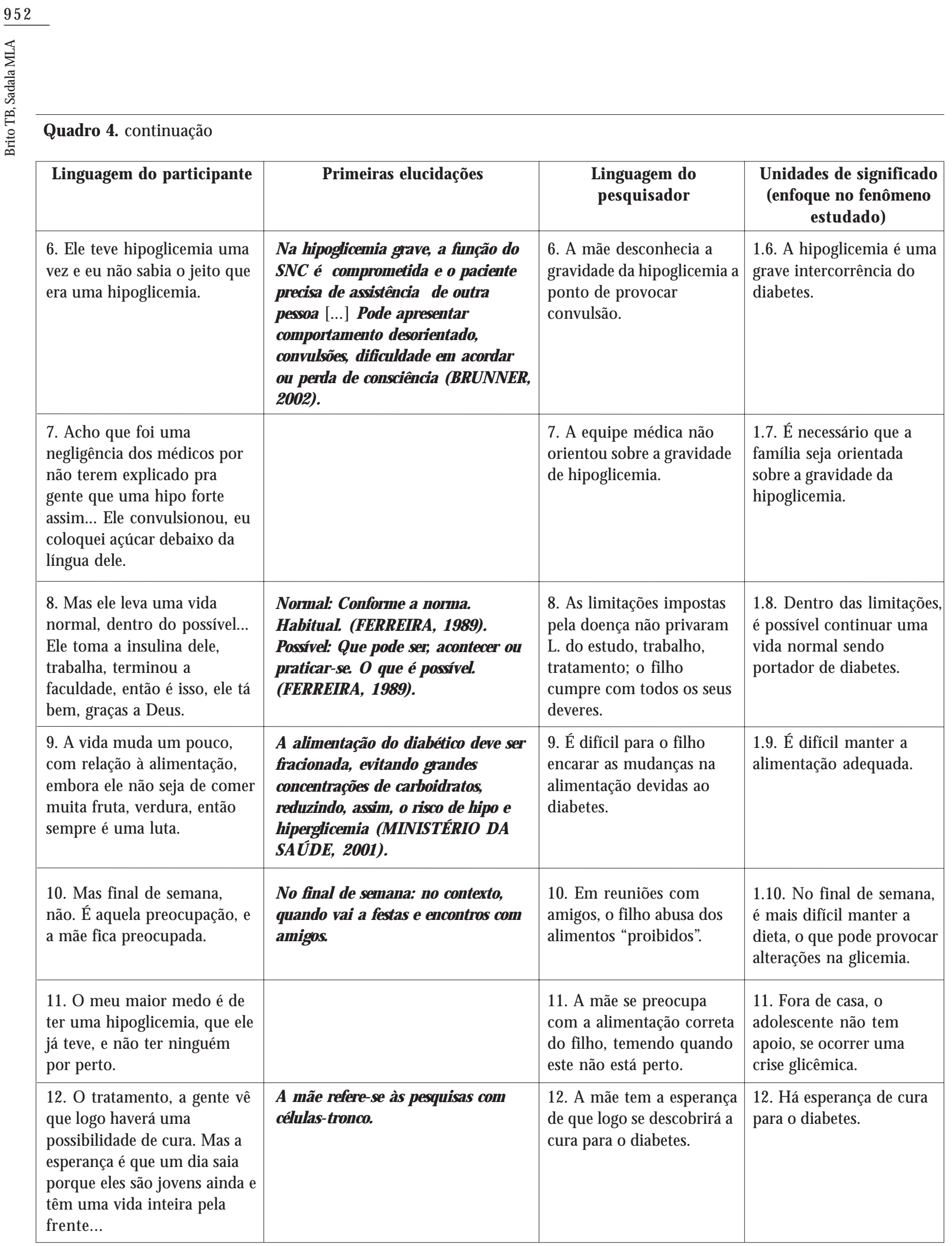

Tratando-se de uma pesquisa qualitativa, o número departicipantes não foi preestabelecido: foram entrevistadas tantas mães (ou pais) quantas necessárias para responder à questão do estudo. Considerou-se ter atingido a saturação dos dados quando começaram a repetir-se, sendo, portanto, suficientes para responder à questão do estudo. 
Quadro 5. Quadro de convergências - análise nomotética.

\begin{tabular}{|c|c|c|c|c|c|c|c|c|c|c|c|}
\hline TEMAS & Convergências Depoimentos & 1 & 2 & 3 & 4 & 5 & 6 & 7 & 8 & 9 & 10 \\
\hline \multirow[t]{7}{*}{$\begin{array}{l}\text { UNIVERSO DA } \\
\text { DOENÇA }\end{array}$} & O início da doença & 1.1 & $\begin{array}{l}2.1 \\
2.3\end{array}$ & 3.1 & $\begin{array}{l}4.1 \\
4.2\end{array}$ & $\begin{array}{l}5.2 \\
5.3\end{array}$ & 6.1 & 7.5 & 8.1 & & 10.1 \\
\hline & Desconhecimento da doença & $\begin{array}{l}1.2 \\
1.7\end{array}$ & 2.2 & 3.15 & 4.6 & 5.1 & & 7.3 & & & \\
\hline & M edo de complicações & $\begin{array}{r}1.5 \\
1.11\end{array}$ & & & & & $\begin{array}{r}6.1 \\
4\end{array}$ & $\begin{array}{l}7.2 \\
7.8\end{array}$ & & & $\begin{array}{l}10.16 \\
10.38\end{array}$ \\
\hline & Aprendendo sobre a doença & 1.7 & & 3.22 & & & & & 8.2 & & 10.7 \\
\hline & Adaptação à doença & $\begin{array}{l}1.2 \\
1.8\end{array}$ & $\begin{array}{l}2.4 \\
2.9\end{array}$ & $\begin{array}{r}3.2 \\
3.4 \\
3.14\end{array}$ & $\begin{array}{r}4.4 \\
4.10\end{array}$ & 5.6 & $\begin{array}{r}6.3 \\
6.1 \\
1\end{array}$ & 7.1 & 8.4 & & $\begin{array}{l}10.21 \\
10.40\end{array}$ \\
\hline & Mudanças no cotidiano & 1.9 & 2.5 & 3.7 & 4.9 & 5.8 & $\begin{array}{r}6.1 \\
0\end{array}$ & & 8.5 & $\begin{array}{l}9.2 \\
9.7\end{array}$ & 10.15 \\
\hline & Dificuldades financeiras & & $\begin{array}{l}2.6 \\
2.8 \\
\end{array}$ & & 4.15 & & 6.7 & 7.4 & & & 10.39 \\
\hline \multirow{5}{*}{$\begin{array}{c}\text { RELAÇÕES } \\
\text { COM AS } \\
\text { PESSOAS }\end{array}$} & Relação da criança com a doença & 1.4 & $\begin{array}{l}2.11 \\
2.23\end{array}$ & $\begin{array}{l}3.17 \\
3.18\end{array}$ & $\begin{array}{l}4.7 \\
4.9\end{array}$ & 5.5 & 6.4 & & $\begin{array}{r}8.1 \\
2\end{array}$ & & $\begin{array}{r}10.2 \\
10.34\end{array}$ \\
\hline & Relação com o filho & 1.10 & 2.10 & 3.4 & $\begin{array}{r}4.5 \\
4.11\end{array}$ & & & & & $\begin{array}{l}9.6 \\
9.8\end{array}$ & $\begin{array}{r}10.3 \\
10.24\end{array}$ \\
\hline & Relação da criança com familiares & & $\begin{array}{l}2.14 \\
2.18\end{array}$ & $\begin{array}{l}3.6 \\
3.9\end{array}$ & 4.14 & 5.5 & & & & & $\begin{array}{r}10.4 \\
10.15\end{array}$ \\
\hline & Relação com os profissionais & & 2.15 & & $\begin{array}{l}4.16 \\
4.17\end{array}$ & 5.3 & $\begin{array}{l}6.5 \\
6.8\end{array}$ & & & & $\begin{array}{r}10.9 \\
10.20\end{array}$ \\
\hline & Relação da criança com colegas & & 2.18 & & & & & & $\begin{array}{r}8.1 \\
8\end{array}$ & $\begin{array}{r}9.3 \\
5\end{array}$ & \\
\hline \multirow[t]{3}{*}{$\begin{array}{c}\text { REFLEXÃO } \\
\text { SOBRE A } \\
\text { EXPERIÊNCIA }\end{array}$} & $\begin{array}{l}\text { Percebendo-se como mãe (pai) da } \\
\text { criança com diabetes }\end{array}$ & & $\begin{array}{l}2.12 \\
2.13\end{array}$ & 3.13 & $\begin{array}{r}4.8 \\
4.13\end{array}$ & 5.6 & & & & & 10.31 \\
\hline & Avaliando o acontecido & 1.2 & 2.20 & $\begin{array}{r}3.5 \\
3.10 \\
3.16\end{array}$ & & & $\begin{array}{r}6.6 \\
6.1 \\
0\end{array}$ & & & & $\begin{array}{r}10.5 \\
10.6 \\
10.23 \\
10.36\end{array}$ \\
\hline & Perspectivas para o futuro & 1.12 & $\begin{array}{r}2.7 \\
2.16\end{array}$ & 3.19 & 4.3 & $\begin{array}{r}5.1 \\
5\end{array}$ & $\begin{array}{r}6.9 \\
6.15\end{array}$ & & & & \\
\hline
\end{tabular}




\section{Construção dosresultados}

As convergências dos discursos foram agrupadas em três temas principais: o universo da doença, relação com as pessoas e reflexão sobre a experiênciavivida.

0 universo da doença

Os participantes descrevem, nos depoimentos, como perceberam os primeiros sinais da doença, antes do diagnóstico médico: o filho apresentava sede insaciável ou emagrecimento súbito. Uma participante descreve:

"O que me chamava à atenção nela era a boca seca, porque minha sogra [diabética] reclamava muito que bebia água e parecia que a boca tava plastificada. E eu percebi que a M. era assim, ela bebia água e a boca não molhava." (P 5).

$O$ diagnóstico de diabetes lança os familiares numa situação assustadora e desconhecida. Aos poucos, tomam conhecimento da extrema gravidade da doença. $N$ as suas descrições, falam sobre desespero e de como se sentem despreparados quando recebem o diagnóstico. Havendo necessidade de internação, vivem uma experiência traumática e marcante. Cada vez mais preocupados e ansiosos, tornam-se cientes da necessidade de tratamento e acompanhamento médico rigorosos.

A partir daí, estabelecem-se novas condições de vida para a criança, impondo-Ihe regime alimentar restritivo, injeções de insulina, supervisão constante dos pais. Tudo isso significando severos limites para suas atividades. A partir daí, a família convive com o temor constante de ocorrerem complicações. As complicações temidas vão desde crises hipoglicêmicas ehiperglicêmicas graves a patologias crônicas associadas à degeneração precoce, como descreve uma das mães:

"Também é muito arriscado, porque se não cuidar direitinho éperigoso! Ela tá com um monte de coisa, né? Esses tempos atrás, morreu um rapaz com 21 anos. Ele teve diabetes com nove anos também. Atacou o coração, porque ataca o coração também, né? E eu e $0 Z$. , a gente fica preocupado com a D." (P 7)

0 impacto do diagnóstico causa sentimentos de negação para os pais, que não aceitam a doença do filho:

"A primeira coisa quea gentesenteéa negação: 'então, trocaram o exame dele, não é ele, amanhã não tem nada a ver, vai dar tudo diferente. $\mathrm{E}$ durante a noite foi a mesma coisa. Você sonha que não aconteceu com você." (P 3)
Os pais percebem que cuidar da criança não é apenas dar as medicações e supervisionar sua alimentação: é preciso ajudá-la a entender a doençae o tratamento e aceitar sua condição. Uma participante relata:

"Tem muitas coisas às vezes que ele duvida. Então você tem que tá um pouquinho mais estudada pra poder questionar, então você tem que tá um pouquinho preparada pra resposta, porque se não ele fala: 'Então se não tem problema eu vou fazer." (P 3).

A aplicação de insulina é considerada um dos maiores problemas no tratamento. É muito agressivo e doloroso, causando resistência da criança ao tratamento. U ma participante diz: "Até hoje ele não aceitou muito bem a insulina".

O correm mudanças drásticas vida da criança e da família. A alimentação éa principal: alteram-se os hábitos al imentares no cotidiano da criança, que passa a encarar o dia-a-dia com grande dificuldade. Isto fica claro na expressão de uma mãe: "Então sempre é uma luta". (P 1) As mudanças impostas pela doença envolvem também os pais e irmãos. A família, como um todo, percebe a necessidade de adaptação à nova realidade: "M uda completamente a rotina da casa, de todo mundo." (P 8).

Trata-se de uma patologia que, por si, já é grave. 0 tratamento, ao impor grandes restrições à vida normal, dificulta a adaptação. Daí as grandes dificuldades que a criança tem ao vivenciar esse momento, pois ela passa por uma idade de grandes transformações. Quando ela atinge a adolescência, as reações típicas desta fase de crescimento associam-se às dificuldades já existentes:

“Foi muito difícil enaadolescência dela foi pior ainda, porque ela não aceitava a doença, a alimentação. Não aceitava tomar a insulina, quer dizer. Ela vinha parar aqui, ruim. Ficava internada na CTI, ficava muito ruim mesmo." (P 6).

As crianças e os familiares convivem, nestecontexto por si penoso, com a incompreensão e falta de apoio: "Chega num lugar [ para ser atendido] a gentefala queeleédiabético e el es não tão nem aí." (P 4). Há ainda os problemas financeiros, pois o tratamento representa um custo significativo no orçamento doméstico. 0 tratamento correto do diabetes exige boa alimentação, controle periódico da glicemia, aplicação de insulina, eas dificuldades financeiras podem impedir ou dificultar o controle da doença. U ma participante conta: "Foi muito duro, porque meu marido ganhava muito pouco, né, e eu também ganhava muito pouco." (P 2)

Quando o filho aceita a doença e não se revolta, o familiar sente-se mais seguro e a convivência 
torna-se mais tranqüila. N o entanto, algumas crianças sentem constrangimento e vergonha em ser portador de diabetes.

"Ele se sente muito rejeitado, na escola. Depois que descobriu, elenão foi mais o que era na escola. Começou a se desinteressar [choro], tirar nota ruim, chorar, sabe? Ele usa a doença e a gente vê que realmente tem hora que é isso, mas a gente é mãe, né? Eu tenho féqueno final dá tudo certo. Ele só falta da escola, não faz a lição porque ele perdeu 0 interesse por tudo, não quer brincar, não quer sair. Então ele fica muito apegado a mim." (P 4).

Segundo os pais, os filhos apresentam sentimentos de revolta e raiva por ficarem doentes. Essas reações prejudicam o tratamento, pois, sentindo-se inferiorizada pela doença, as crianças/adolescentes escondem sintomas de hiper ou hipoglicemia. Um familiar relata: "Ele tem vergonha de dizer perto dos outros que não tá bem" (P 2), manifestando angústia pelo constrangimento e desconforto do filho.

\section{Relação com as pessoas}

Alguns pais exacerbam o relacionamento de dependência com o filho. Procurando protegê-lo, passam a conduzir as próprias vidas em função do cuidado do filho. Restringem, assim, a sua própria autonomia e a dele, ambos tornando-se extremamente dependentes:

“É aquela preocupação, ea mãefica preocupada. Toda vez que sai, viaja, a gente pede pra avisar onde tá, horário que saiu, horário que chegou." (P 1).

Alguns pais procuram aproximar-se e compreender a criança, tentando diminuir seu estresse. N este sentido, transcendem sua angústia e seus sentimentos de desvalia, mostrando disposição para apoiar o filho e lutar ao seu lado. Ao fazer isso, têm o intuito de abrir-Ihe perspectivas novas, para que se conscientize de que não há apenas a doença, mas há uma vida a ser vivida: "Aí vem aquela segunda fase, que você sabe que vai ter que ser forte de qualquer jeito, que seu filho vai precisar da sua força. Então eu não tinha chance de me abater. Eu tinha que passar pra ele que ele tinha um problema de saúde, mas que ele tinha a vida inteira pela frente." (P 3).

$\mathrm{Na}$ convivência familiar, a situação da doença provoca conflitos entre os irmãos, que se recusam a mudar os hábitos alimentares em função do familiar doente. Além disso, competem pela atenção dos pais, como descreve um participante: "Acarreta problemas em geral, porque eu tenho um filho mais vel ho eum mais novo. Eleéo do meio. Então acontece a cobrança dos outros filhos." (P 10)
Alguns pais constatam que é importante para a criança/adolescente ser tratada igualmente no meio dos irmãos: "Lá em casa a gente tenta tratálo da maneira mais natural possível. Ele leva bronca, castigo, tudo normal porque eu percebi que assim ele se sente melhor, do que a gente ficar protegendo, cercando de mimos." (P 3). Da mesma forma, o apoio dos colegas facilita o tratamento: "As amiguinhas, se ela vai a festas, ajudam ela a não comer o que não pode. Todo mundo colabora um pouco pra ficar fácil pra ela." (P5)

\section{Reflexão sobre a experiência}

Ao analisar a experiência, como um todo, os pais descrevem sentimentos diversos. Alguns se sentem tranqüilos por estar cumprindo seu papel. Relatam queo tratamento do diabetes depende $50 \%$ da criança e $50 \%$ do apoio familiar, estan do garantida a sua participação: "Eu faço a minha parte, eu sou responsável por $50 \%$, os outros édele!" (P 10)

Muitos falam da sua impotência diante da gravidadee complexidade da doença. Sentem-sedesarmados diante do inevitável. Não vêem solução para quese restabeleça o bem-estar do filho. Um familiar queixa-se: "Por mais que você faça, tá sempre faltando alguma coisa." (P 10). Uma participante atribui a si, como mãe, a maior responsabilidade pelo cuidado do filho, salientando o seu papel de maior empatia eamizade com a criança e descrevendo seu papel como polivalente: mãe, enfermeira, amiga: "A gente tem que ser tudo." (P 8). Esta mãe expressa um entendimento comum sobre o papel da mãe junto aos filhos. Os resultados do estudo mostram que a responsabilidade de aplicação de insulina e a conseqüente concentração no cuidado são atribuídas às mães, devido à sua participação diária na vida do filho. Observamos que, entre os participantes, nove são mães. São as mães que levam os filhos às consultas médicas, que frequentemente fazem anotação relacionadaà dieta e, ainda, acompanham grupos de educação em diabetes.

Muitos participantes avaliam que é essencial, para a família, aceitar a doença do filho e adaptarse, para que realmente possam ajudá-lo. N este movimento, a meta é estimulá-lo a visualizar suas possibilidades de viver da melhor forma possível: "Eu falei pra ele que a diabetes tirou algumas coisas da vida dele, mas que não pode tirar o resto, e ele não pode deixar. Então é mais ou menos assim que a gente trabalha com o G." (P 3)

$N$ ão controlar a doença aproxima a criança/ adolescente das complicações: "O DR S. segurou ele um pouco lá a cada três meses. [A glicemia] tá sempre alta, em jejum 500 e pouco, é sempre as- 
sim. Então ele chegou num ponto que ou ele vai cegar. Já tá tomando remédio pro rim, mas também não tomou mais. Tudo é assim, tudo que é pra ele fazer ele não faz." (P 10)

Diante da situação e das dificuldades impostas pela doença, que, atualmente, não tem perspectiva de cura, é preciso aceitar e continuar a vida: "A gente vai levando." (P 1). Não obstante, alguns familiares acreditam nessa possibilidade: "O tratamento, a gente vê que logo haverá uma possibilidade de cura, mas acho que tem muito comércio dos laboratórios nisso, e não saiu nada ainda. M as a esperança é que um dia saia, porque eles são jovens ainda e têm uma vida inteira pela frente. $E$ a gente tá torcendo por isso!" (P 1).

Enquanto essestêm esperança nos avançoscientíficos, outros se confortam com a fé religiosa: "Cura ainda não tem, só D eus pra curar. E enquanto isso não acontece, tem que seguir em frente porquea vida continua. É queeu falo praele,que a vida continua". (P 4)

A religião, evocada por esta mãe, simboliza a esperança, contribuindo para a aceitação ecompreensão da situação da doença crônica, que afetou e transformou profundamente a vida do seu filho. Outros pais mostram inconformismo com o inevitável. Só enxergam a cronicidade da doença e a dificuldade em ter que conviver com ela: "Graças a Deus ele está bem, mas é duro saber que é uma coisa que vai ter que conviver pro resto da vida." (P 2)

Apesar das limitações decorrentes da patologia e pelo tratamento, é preciso estimular o filho a continuar a vida. Uma participante conta que insiste com o filho sobre as dificuldades que Ihe são impostas pela doença, mas sempre o encoraja a não desistir: "Elenão podedeixar de viver por causa disso". (P 3)

\section{Síntese compreensiva}

Os três temas que emergiram das descrições dos participantes mostram quão complexa éa situação vivida pelos pais. Confrontam-se, repentinamente, com o evento do diabetes tipo I na vida do seu filho e precisam conscientizar-se de que se trata de uma grave doença crônica, alterando a sua existência em todas as dimensões. As dramáticas transformações que a doença provoca, extensiva a todos os membros da família, são descritas em todos os depoimentos. Assim como a constantepresença do medo, do sentimento de impotência, do próprio despreparo dos familiares para enfrentar a situação. Esses dados são similares a resultados descritos em estudos anteriores sobre 0 tema ${ }^{11-15}$.
Para os participantes do estudo, o diagnóstico da doença é um marco definitivo. Há um tempo vivido a partir do diagnóstico do diabetes: ali, a vida se transformou. Na rotina cotidiana, mudaram os hábitos e as obrigações, mudaram as prioridades. A partir dali, são novas regras e normas, que devem ser seguidas rigidamente, sob a pena de haver graves complicações no estado de saúde do filho. Passa-se a conviver com o medo constante das graves complicações, decorrentes de um diabetes mal controlado. Experimenta-se a angústia de não saber se o filho viverá bem no futuro, ou se viverá. Ainda há as implicações econômicas. Os medicamentos e a alimentação especial exigem maiores gastos para a família, que, muitas vezes, já se encontram no limite de suas possibilidades financeiras. Esta problemática de âmbito pessoal e familiar insere-se num contexto também complexo: 0 da assistência à saúde, com suas limitações, restrições, dificuldades de atendimento e necessidade de tempo extra disponível na vida dos pais, já sobrecarregados no seu tempo integral de dedicação ao trabalho e à família.

O tempo vivido a partir do conhecimento da doença do filho é o tempo da surpresa, do temor, da espera pelo pior. Vivem a ansiedade e a incerteza do que virá ao sabor da evolução dessa grave doença degenerativa. Vivem a incerteza de como será o futuro do filho.

Dados da literatura assemelham-se a esses resultados: mesmo orientadas quanto ao controle da doença e aos cuidados preventivos, mães de crianças com diabetes sentem-se incompetentes diante do acontecimento e despreparadas para lidar com a situação ${ }^{12-16}$. Zanetti ${ }^{14}$ observou alta frequência deansiedade em pais decrianças diabéticas, devido à não aceitação da doença do filho e/ou ao sentimento de culpa pelo fator hereditário envolvido na doença. 0 sentimento de revolta e desespero foi também encontrado em estudo seguinte ${ }^{15}$.

Sobre as dificuldades em aceitar a doença e 0 tratamento, os dados encontrados assemelhamse aos de estudos anteriores: adolescentes portadores de doença crônica sentem-se diferentes e socialmente mais restritos do que colegas da mesma idade e sem a doen ça ${ }^{17-19}$. Esses sentimentos de inferioridade também foram encontrados no estudo de Silva ${ }^{20} \mathrm{e} M$ artinez et al. ${ }^{21}$, podendo ser explicados pel os cuidados e vigilância constantes, por parte dos pais, exigidos no controle da doença. 0 adolescente diabético pode viver uma relação ambígua com sua doença, pois vive um momento em quedesafiar o mundo faz parte do desenvolvimento desua individualidade ${ }^{22}$. Quando este desafio acontece em relação ao diabetes, 0 adolescente pode 
praticar abusos, principalmentedo álcool, querendo provar a si mesmo que "essa maldita doença", que está dentro dele, não o impede deviver. Provavelmente, pensar e agir assim trará graves conse quências, inclusive a morte ${ }^{23}$. Por outro lado, de pendendo de como a doença se manifesta e do significado que a doença tem na fantasia do paciente, pode interferir no seu "eu", auto-estima, qualidade de vida, capacidade de amar, de ter esperanças. M esmo aqueles mais adaptados têm uma dose de revolta por trás de sua tolerância, pois ninguém quer ficar doente ${ }^{24}$.

Em relação à dieta proposta para o tratamento, a transgressão alimentar está, de algum modo, sempre presente no inconsciente do paciente diabético, bem como na sua maneira de driblar o profissional da saúde e o seu principal cuidador ${ }^{25}$. A terapia nutricional éum componenteessencial para o tratamento bem-sucedido do diabetes. 0 plano alimentar deve fornecer calorias suficientes para manter ou al cançar índices de crescimento edesenvolvimento normais em crianças e adolescentes. Ao mesmo tempo, manter equilíbrio entre o consumo de alimentos e a insulina disponível, fornecer alimentação nutricionalmente equilibrada, de acordo com as necessidades individuais, e manter bom controle metabólico para prevenir e/ou re tardar complicações agudas e crônicas, para assim proporcionar qualidade de vida ao portador de diabetes. 0 fracionamento das refeições em seis porções deve ser realizado, aliado à insulinização, atividade física e a disponibilidade de horário para refeição $0^{25}$.

Sobre as dificuldades da criança/adolescente com a aplicação de insulina, comentadas por muitos pais neste estudo, atualmente desenvolvem-se estudos e pesquisas experimentando o uso da insulina inalável, a fim de diminuir o incômodo das picadas diárias da aplicação desse hormônio. Os estudos têm mostrado bons resultados, como melhor controle glicêmico. No entanto, a terapia com a insulina inalável não substitui o uso das picadas de insulina subcutânea. Trata-se de uma alternativa coadjuvante no controle do diabetes tipo 1, para pacientes resistentes ao uso deinsulina pré prandial26-28.

\section{Relação com as pessoas}

Diante das dificuldades da criança/adolescente em aceitar a doença e lidar com os novos hábitos impostos pelo tratamento, os pais têm dificuldades nesse novo papel: percebem-se como fiscalizadores, privando os filhos da sua vida normal. Percebem-se também como incapazes delhes oferecer o que é o principal papel dos pais: garantir-lhes segurança e um futuro. Para eles, cresce, além das suas possibilidades, a função de guardião do filho. Declaram-se impotentes diante da inevitabilidade da doença em seu curso. É uma doença que veio para ficar e é preciso ajudar o filho a viver com ela. $M$ ais do que isso: aceitá-la. Como fazer isso quando, para os pais, essa realidade é inaceitável?

Alguns estudos ${ }^{29,30}$ analisam a dinâmica familiar vivida pelo paciente diabético e seus pais, descrevendo a superproteção aos filhos, principalmente no caso de crianças menores. Seria uma forma de os familiares encobrirem uma rejeição inconsciente. Em conseqüência da superproteção dos pais, a criança apresentaria instabilidade de humor com irritabilidade, imaturidade afetiva que se traduz por grande necessidade de proteção, fal ta de confiança em si e uma dependência enorme dos pais ${ }^{30}$. Outros estudos ${ }^{15,} 31$ acreditam em um aspecto positivo da superproteção, que seria obter o melhor controle da glicemia. Ao fazer isso, no entanto, não descartam o esmagamento da personalidade da criança. Possivelmentemensagens deincentivo, tais como sobre os ganhos pessoais com o tratamento, poderiam ser mais efetivas para aumentar a aderência que mensagens de ameaças ${ }^{30}$. Estudo realizado por Verena et al. ${ }^{31}$ reafirma a importância da motivação da criança/adolescente na realização de atividades que culminarão com o bom controleglicêmico e, como resultado, melhor qualidade de vida.

$\mathrm{N}$ ão obstante sentirem angústia diante das manifestações dos filhos, os pais, conscientes de serem o seu apoio, lutam para não fraquejar. Permanecem fortes junto dos filhos ${ }^{12}$. As descrições dos pais, neste sentido, nos remetem à reflexão sobre as várias formas de cuidar do outro, descritas por H eidegger ${ }^{32}$. Ele descreve duas possibilidades desse cuidado: saltar sobre o outro, fazer tudo por ele e dominá-lo - o que desenvolveria um relacionamento autoritário e de dependência; e saltar diante do outro, estimulando-o a assumir seus atose a ser ele mesmo - o que promoveria a independência no cuidar-se. Esta última possibilidaderefere-se ao autêntico "cuidar promovendo o outro". Vivendo as experiências e expectativas com o filho, alguns pais se despojam do seu "eu", para, junto com o filho, tornar-se "nós"; são pre-sença e co-participam de suas vivências. Esse encontro com o outro, segundo Heidegger, é determinação da pre-sença, pois o mundo da pré-sença é um mundo compartilhado. "O ser-em é ser- com os outros". O serem-si intramundano desses outros é co-presença ${ }^{32}$.

Além do suporte da família, o suporte vindo dos amigos tem o mesmo objetivo: ajudar a crian- 
ça/adolescente com doença crônica a se ajustar psicologicamente à sua doença e saber conviver com ela ${ }^{33-35}$. A presença dos amigos proporcionariaà criança eao adolescente 0 elo quelhe assegura os vínculos com o "seu mundo", assegurando-Ihe que ainda pertence a esse mundo $0^{34}$.

Dados da literatura sobre o tema sugerem a formação de grupos familiares de apoio ao tratamento como uma estratégia essencial no cuidado das crianças portadoras de diabetes. N esses grupos, conduzidos pela equipe que acompanha a criança, os familiares se apóiam mutuamente, aprendendo formas novas de lidar com a situação, de seguir as orientações e de monitorar a evolução do diabetes $2,15,16,25$.

\section{Reflexão sobre a experiência}

Cuidar do filho com diabetes desvela-se neste estudo como uma resposta dos pais às necessidades do filho, que depende das ações paternas. 0 cuidado do outro pode ser compreendido como uma complexa relação emocional de resposta a um pedido de ajuda, implicando assumir uma responsabilidade pela pessoa de quem se cuida. Van M anen ${ }^{35}$ considera que quanto mais se cuida de uma pessoa, mais cresce a preocupação e o envolvimento com ela, emais crescea dedicação desse cuidado. Devido ao genuíno relacionamento de cuidar entre pais efilhos, este cuidado-preocupação éa base para compreender a prática verdadeira de cuidar dos pais que participaram este estudo. Eles se preocupam com os filhos em todas as instâncias: sua saúde física e mental, seu bem-estar social, seu futuro, seus sentimentos e inseguranças; e o que podem e poderão fazer por eles, hoje e para o futuro. Preocupam-se com as condições da sua assistência e com as perspectivas do que virá para melhorar sua condição devida. Alguns esperam pela cura do diabetes, antevendo grandes evoluções científicas no tratamento das doenças crônicas incuráveis. Sonham com o que parece impossível no momento.

Sobre essas possibilidades futuras, atualmente existem cinco linhas de pesquisa visando à cura do diabetes: 1. transplante pancreático; 2 . transplante de ilhotas; 3 . bioengenharia com células tronco e afins; 4. pâncreas virtual; 5. regeneração deilhotas. Desde 2000, tem sido pesquisado o transplante de ilhotas. Há também a busca por novas emelhores drogas imunossupressoras ${ }^{36}$.
Estudo recente desenvolvido por pesquisadores do Centro de Terapia Celular da USP-Ribeirão Preto, testou a terapia do auto-transplante de medula óssea associada à imunossupressão por quimioterápicos. Os resultados foram positivos: dos quinze pacientes, catorze deixaram de fazer uso de insulina e, portanto, voltaram a produzir o hormônio; no entanto, é preciso constatar se os efeitos serão duradouros. Os pesquisadores prevêem o uso de células-tronco mesenquimais, cuja característica de depressão imunológica prescindiria o uso dos quimioterápicos, tornando a terapia menos agressiva ${ }^{37}$.

$\mathrm{Na}$ expectativa dos avanços científicos para a cura da doença, ou de ajuda divina, os pais tentam superar um presente de sofrimento e dificuldades. N essa trajetória, mostram a tensão que vivenciam: de um lado, a angústia, seus sentimentos de impotência diante da facticidade da doença; de outro lado, a constanteintenção decuidar e ajudar o filho, e, ao fazer isso, vislumbrar possibilidades e perspectivas melhores para o seu futuro. Eles constatam que a doença priva a criança/jovem de uma vida normal, mas acreditam que elas podem ainda usufruir uma vida longa, ativa e feliz.

\section{Consideraçõesfinais}

Os resultados deste estudo, de natureza qualitativa - contextualizado no tempo e local da sua realização, não pretendendo, portanto, generalizações - trazem contribuição significativa para compreender as verdades gerais sobre cuidar do filho com diabetes tipo I. 0 enfoque fenomenológico, que parte da descrição da experiência de doença vivida pelas pessoas, sugere nova abordagem para a compreensão das necessidades desses familiares, de uma perspectiva individual, permitindo a visão das suas formas peculiares de lidar com conflitose ansiedades, gerados com o evento do diabetes tipo 1, na sua família. Conseqüentemente a esses dados, emerge a necessidade de se integrarem as famílias de crianças e adolescentes, portadores de diabetes, no planejamento e implementação deste cuidado. Neste sentido, ressalta-se a importância do papel desempenhado pelos profissionais da saúde, na assistência e prevenção às complicações da doença. 


\section{Colaboradores}

TB deBrito eM LA Sadala participaram igualmente de todas as etapas da elaboração do artigo.

\section{Referências}

1. Fundo Nacional de Saúde. FUNASA. Diabetes M ellitus [monografia da Internet] 2003. [acessado 2003 set 11]. Disponível em: http://www.funasa.gov.br.

2. Luce M, Padilha MI, Almeida RLV, Silva M. O preparo para o auto-cuidado do cliente diabético e família. Rev Esc Enferm USP São Paulo 1991; 25:135-152.

3. Althoff CR, Elsen I, Laurindo C. Família: o foco de cuidado na enfermagem. Texto \& Contexto Enferm 1998; 7:320-327.

4. Pace $A E$, Nunes PD, Ochoa-Vigo K. O conhecimento dos familiares acerca da problemática do portador de diabetes mellitus. Rev Latinoam Enferm Ribeirão Preto 2003; 11:312-319.

5. Ghelman LG. 0 cotidiano de crianças diabéticas: vivido de mães e assistência da enfermeira [dissertação]. Rio de Janeiro (RJ): Escola de Enfermagem Anna Nery, Departamento de Saúde Pública; 2000.

6. Damião $E$, Ângelo M. A experiência da família ao conviver com a doença crônica da criança. Rev Esc Enferm USP São Paulo 2001; 35:66-71.

7. Silva LF. Doença crônica: o enfrentamento pela família. Acta Paul Enferm 2002; (1):40-47.

8. Elsen I, M arcon SS, Silva MRS, organizadores. 0 viver em família e sua interface com a saúde e a doença. M aringá: Editora da U niversidade Estadual de Maringá; 2002.

9. Martins J, Bicudo MAV. A pesquisa qualitativa em psicologia: fundamentos e recursos básicos. São Paulo: M oraes; 1989.

10. M erleau Ponty M. La phénoménologie de la perception. Paris: Gallimard; 1945.

11. Armond LC, Boemer MR. Convivendo com a hospitalização do filho adolescente. Rev Latinoam Enferm 2004; 12:924-932

12. Sullivan-Bolyai S, Deatrick J, Gruppuso P, Tamborlane W, Grey M. Constant vigilance: mother's work parenting Young children with type 1 diabetes. J Pediatr N urs 2003; 18:21-29.

13. Sullivan-Bolyai S, Deatrick J, Gruppuso P, Tamborlane W, Grey M. M other's experiences raising young children with type 1 diabetes. J Spec Pediatr N urs 2002; 7:93-103.

14. Zanetti ML. Análise das dificuldades relacionadas ás atividades diárias de crianças e adolescentes com diabetes mellitus tipo 1: depoimento de mães. Rev Latinoam Enferm 2001; 9(6):25:30.

15. Zanetti ML. 0 diabetes mellitus tipo 1 em crianças e adolescentes: um estudo para as mães e profissionais da saúde [monografia da Internet]. 1996 [acessado 2003 jun 15]. Disponível em: http://www.eerp.usp.br/ aefund/resumo/doutor frame-1.htm

16. Seiffge-Krenke I. The coping, burden and their psychological consequences of families with a child with a chronic disease. Stuttgart: Kohlhammer; 1996.

17. Tijhuis MAR, Flap HD, Foets HD, Groenewegen PP. Selection in the social network: effects of chronic illness. Eur J Public Health 1998; 8:286-293.

18. Graetz BW, Shute RH, Sawyer M G. An Australian study of adolescents with cystic fibrosis perceived supportive and nonsupportive behaviors from families and friends and psychological adjustment. J Adolesc $\mathrm{H}$ ealth 2000; 26:64-69.

19. Carson AR, Voorhes HK. Adult pediatric patients. Am J Nurs 2001; 101:46-55. 
20. Silva MAD. Quem ama não adoece. São Paulo: Best Seller; 1994.

21. Martinez CHJ, Lastra MI, Luzuriaga TC. Psychossocial characteristics of children and adolescent with diabetes mellitus. An Esp Pediatr 2001; 55(5):406-412.

22. Ajuriaguerra MN. Manual de psiquiatria infantil. $2^{\text {a }}$ ed. Rio de janeiro: Masson do Brasil; 1976.

23. Gonçalves LB. Diabetes juvenil: a importância dos pais. Pediatr M od 2000; 36:334-335.

24. Grupo de Estudos em Endocrinologia e Diabetes. Diabetes - objetivando controle e educação. Endocrinol Diabetes Clín Exp 2000; 1:43-44.

25. Brasil. Ministério da Saúde. Abordagem Nutricional em Diabetes M ellitus. Brasília: M inistério da Saúde; 2000.

26. Skyler JS, Weinstock RS, Raskin P, Yale JF, Barret E, Gerich JE, Gerstein HC; Inhaled Insulin Phase III Type 1 Diabetes Study Group. Use of Inhaled Insulin in a Basal/Bolus Insulin Regimen in Type 1 Diabetic Subjects, USA. Diabetes Care 2005; 28(7):1630-1635.

27. Quattrin T, Belanger A, Bohannon NJ, Schwarttz SL. Efficacy and safety of inhaled insulin (Exubera) compared with subcutaneous insulin therapy in patients with type 1 diabetes: results of a 6 month, randomizes, comparative trial. Diabetes Care 2004; 27: 2622-2627.

28. Ceglia L, Lau J, Pittas AG. Meta - Analysis: efficacy and safety of inhaled insulin therapy in adults with Diabetes M ellitus. Ann Intern M ed 2006; 145:665-675.

29. Helvi K. Support network of adolescents with chronic disease: adolescent's perspective. Nurs Health Sci 2004; 6:287-293.

30. Anjos MN. A criança diabética. 3ạ ed. Rio de Janeiro: Cultura M édica; 1982.

31. Verena M W, Godeffroy EM, Sengbusch S, Häger S, Thyen $U$. Age, metabolic control and type of insulin regime influences health-related quality of life in children and adolescents with type 1 diabetes mellitus, Germany. Eur J Pediatr 2005; 164:491-496.
32. Heidegger $M$. Todos nós... ninguém: um enfoque fenomenológico do social. São Paulo: Moraes; 1981.

33. Graetz BW, Shute RH, Sawyer M G. An Australian study of adolescents with cystic fibrosis perceived supportive and nonsupportive behaviors from families and friends and psychological adjustment. J Adolesc Health 2000; 26:64-69.

34. Woodgate RL. Adolescent's perspective of chronic illness: its hard. J Pediatr N urs 1998; 13:210-223.

35. Van Manen M. Care-as-worry, or "don't worry be happy". Qual Health Res 2002, 12(2):262-278.

36. Wasikowa R, Noczynska A, Basiak A. Transplantation in diabetes type 1-current problems and perspectives. Endokrynol Diabetol Chor Przemiany M ateru Wieku Rosw 2004; 10(2):119-122.

37. Voltarelli JC, Couri CEB, Stracieri ABPL, Oliveira MC, Moraes DA, Pieroni $F$, Coutinho $M$, Malmegrim KC, Foss-Freitas MC, Simões BP, Foss MC, Squiers E, Burt RK. Autologus Nonmyeloblative Hematopoietic Stem Cell Transplantation in Newly Diagnosed Type 1 Diabetes Mellitus, USA. J Am Med Assoc 2007; 297(14):1568-1576.

Artigo apresentado em 26/04/2006

Aprovado em 25/06/2007

Versão final apresentada em 18/09/2007 